\title{
APLICAÇÃO DE HORSERADISH PEROXIDASE IMOBILIZADA NA DESCOLORAÇÃO DE AZUL DE METILENO
}

\author{
A. BASTOS ${ }^{3}$, P. S.CORREIA ${ }^{3}$, S. G. DE LIMA ${ }^{3}$, A. R. PEREIRA ${ }^{1}$, \\ L. YOKOYAMA ${ }^{2}$, E. M. ALHADEFF ${ }^{3}$ \\ ${ }^{1}$ Universidade Federal do Rio de Janeiro, Tecnologia de Processos Químicos e Bioquímicos, \\ doutorando. \\ ${ }^{2}$ Universidade Federal do Rio de Janeiro, EQ/Departamento de Processos Inorgânicos \\ ${ }^{3}$ Universidade Federal do Rio de Janeiro, EQ/Departamento de Engenharia Bioquímica \\ E-mail para contato: ema@eq.ufrj.br
}

\begin{abstract}
RESUMO - Atualmente, a aplicação de tratamento enzimático em efluentes líquidos proveniente da indústria têxtil tem sido objeto de investigação. Enzimas de oxirredução como lacases e peroxidases são estudadas como potenciais agentes de descoloração e degradação de corantes. O presente trabalho avaliou o potencial da ação da enzima Horseradish peroxidase (HRP), imobilizada em alginato de cálcio, na remoção de cor do corante azul de metileno. Os experimentos foram conduzidos a $30^{\circ} \mathrm{C}$ e $\mathrm{pH} 5,0$; sob agitação constante a $100 \mathrm{rpm}$. Foram testados diferentes tempos de imobilização: 60 minutos, 120 minutos e 24 horas; concentração de enzima imobilizada de 25 e 50 U/mL; reutilização da enzima imobilizada com intervalo 24 horas. O maior percentual de remoção de cor foi cerca de $20 \%$, com concentrações de $50 \mathrm{U} / \mathrm{mL}$, de $6 \mathrm{mg} / \mathrm{L}$, e de $15 \mathrm{mg} / \mathrm{L}$, respectivamente, de enzima, peróxido de hidrogênio e corante, para 2 ciclos de reutilização. Experimentos estão em andamento visando melhor desempenho da enzima imobilizada.
\end{abstract}

\section{INTRODUÇÃO}

O uso de corantes é uma prática extensivamente utilizada na indústria têxtil, gráfica e fotográfica. Cerca de 10.000 corantes e pigmentos diferentes são aplicados industrialmente. E são constituídos de estruturas moleculares aromáticas complexas, inertes e de difícil degradação ao serem lançados no meio ambiente. Desta forma, o tratamento de águas provenientes da indústria têxtil, da fabricação de corantes e semelhantes é um desafio que visa propiciar a descoloração em efluentes industriais (Kunz et al., 2002).

Um dos corantes de maior aplicação na indústria têxtil é o azul de metileno, que se ingerido ou inalado por humanos ou animais pode ser prejudicial. É um corante classificado como básico e pertence à classe das fenotiazinas. É orgânico, aromático, heterocíclico e solúvel em água ou álcool. Ao solubilizar em água produz cátions, podendo ser chamado também de catiônico, apresentando alta reatividade. Na Figura 1 esta representada a estrutura química do azul de metileno na forma de cloreto que tem massa molar de $319.85 \mathrm{~g} / \mathrm{mol}$. Ao aquecê-lo poderá formar óxidos de enxofre e nítrico, causando efeitos toxicológicos ambientais (Hameed et al., 2007). 
<smiles></smiles>

Figura 1. Estrutura química do azul de metileno.

Entre os tratamentos de efluentes líquidos existentes, os processos oxidativos avançados (POA) se apresentam como potencial alternativo ou complementar aos processos tradicionais, se estabelecendo como tecnologia aplicável. Os processos oxidativos enzimáticos envolvem reações de oxiredução (transferência de elétrons), as chamadas oxirredutases, e entre elas as peroxidases. A literatura cita a enzima Horseradish peroxidase como adequada no tratamento de águas residuais pelo fato desta apresentar atividade em ampla faixa de $\mathrm{pH}$ e temperatura (Silva et al., 2012). As técnicas de imobilização de enzimas podem viabilizar o uso e aplicação desta tecnologia em tratamento de resíduos. A reutilização de enzimas imobilizadas em operações sequenciais ou em sistemas contínuos de processo visa reduzir custos inerentes ao do catalisador biológico e de redução de carga orgânica presente no efluente tratado. A imobilização de enzimas possibilita minimizar os efeitos de redução da atividade catalítica e de estabilidade devido a natureza complexa dos efluentes (Mugdha e Usha, 2012).

\section{MATERIAIS E MÉTODOS}

\subsection{Enzima}

Foi utilizada a enzima Horseradish peroxidase (HRP) (EC 1.11.17), gentilmente cedida pela Toyobo do Brasil em sua forma liofilizada.

\subsection{Purificação da Enzima}

A massa de enzima a ser purificada foi suspensa em tampão fosfato $\mathrm{pH}$ 7,0, filtrada em papel de filtro grau qualitativo (INLAB) e colocada na membrana de diálise SPECTRUM® $(12000$ a 14000 kDaltons). A membrana contendo a solução de enzima foi mantida a cerca de $8^{\circ} \mathrm{C}$ imersa em água deionizada, que foi trocada a cada 12 horas durante 24 horas. A enzima purificada foi mantida no freezer, sendo descongelada antes de seu uso.

\subsection{Medida de Atividade}

A atividade enzimática foi determinada pelo método descrito por Nicell e Wright (1997).

\subsection{Imobilização da Horseradish peroxidase}

O método de envolvimento da enzima em gel de alginato de cálcio foi adotado no procedimento de imobilização, utilizando alginato de sódio (Sigma) e cloreto de cálcio (Vetec) 0,1M. Para o preparo do gel de alginato de cálcio (2\%), foram pesados 0,4 gramas de alginato de sódio e dissolvidos em 20 
mL de água destilada. A solução de HRP foi adicionada no gel de alginato de cálcio, de acordo com a concentração desejada ( 25 ou $50 \mathrm{U} / \mathrm{mL}$ ), homogeneizada e a solução de gel e HRP foi gotejada em $100 \mathrm{~mL}$ de cloreto de cálcio (0,1 M), através de uma seringa (Figura 2-a). Após um tempo de cura as esferas (Figura 2-b) foram retiradas e utilizadas nas reações com o corante azul de metileno.
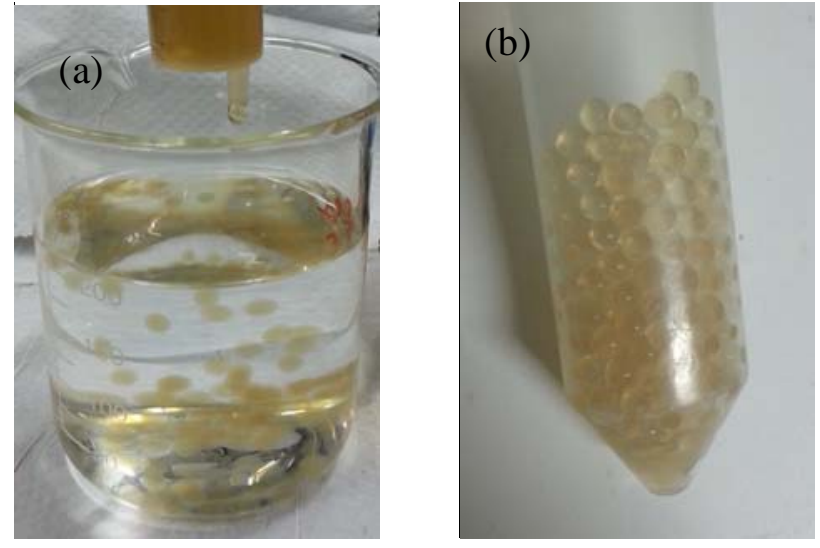

Figura 2. Imobilização da HRP em alginato de cálcio (a). Esferas após 120 minutos de preparo (b).

\subsection{Determinação do teor de descoloração da solução do corante.}

Azul de metileno (VETEC) em solução aquosa na concentração de 15 mg/L foi preparada e utilizada nos testes de descoloração enzimática. $20 \mathrm{~mL}$ de solução de azul de metileno preprada em tampão fosfato $\mathrm{pH}$ 5,0, e $200 \mu \mathrm{L}$ de solução de peróxido de hidrogênio (6 mg/L) são adicionadas em um tubo falcon de $50 \mathrm{~mL}$. A HRP imobilizada foi utilizada de forma a se ter atividade inicial de 25 ou $50 \mathrm{U} / \mathrm{mL}$. O tubo falcon fechado foi então colocado em shaker (Nova Ética, modelo 430/RDBP) sob agitação constante (100 rpm) e, a cada 60 minutos, retiradas alíquotas para análise. A análise da descoloração do azul de metileno foi realizada através da medida da absorbância em $660 \mathrm{~nm}$ antes e após o término da reação em espectrofotômetro UV (SHIMADZU - Modelo UV MINI1240). O pico observado em $660 \mathrm{~nm}$ é característico do corante azul de metileno e sua altura proporcional à concentração na solução. O percentual de descoloração foi calculado de acordo com a Equação 1, na qual $A_{i}$ corresponde à absorbância inicial da solução do corante, no início da reação, e $A_{f}$ representa $o$ valor da absorbância no final da reação, após 60 minutos (Onder et al., 2011).

$$
\text { Remoção de cor }(\%)=\frac{\mathrm{Abs}_{\mathrm{i}}-\mathrm{Abs}_{\mathrm{f}}}{\mathrm{Abs}_{\mathrm{i}}} * 100
$$




\subsection{Ensaios de descoloração.}

\section{Concentração de solução de azul de metileno.}

Foram realizados ensaios visando avaliar a concentração de corante de azul de metileno preparada em tampão fosfato pH 5,0 nas concentrações de 5, 10, 15 e $20 \mathrm{mg} / \mathrm{L}$, com enzima imobilizada ( $25 \mathrm{U} / \mathrm{mL})$ em alginato de cálcio $1 \%$, a $30^{\circ} \mathrm{C}$, a $200 \mathrm{rpm}$ por 60 minutos, e solução de peróxido de hidrogênio de $6 \mathrm{mg} / \mathrm{L}$.

\section{Concentração de solução de peróxido de hidrogênio.}

Foram realizados ensaios visando avaliar a concentração de peróxido de hidrogênio preparada nas concentrações de 0, 6, 9 e $12 \mathrm{mg} / \mathrm{L}$, com enzima imobilizada (50 U/mL) em alginato de cálcio $1 \%$, a $30^{\circ} \mathrm{C}$, a $200 \mathrm{rpm}$ por 180 minutos, e solução de azul de metileno de $15 \mathrm{mg} / \mathrm{L}$.

Experimento controle foi conduzido nas mesmas condições ambientais, porém com esferas de alginato de cálcio sem enzimas, para avaliar o percentual de cor removido apenas por adsorção.

\subsection{Influência do tempo de cura.}

O tempo (60 e 120 minutos) de manutenção da esfera de alginato de cálcio (2\%) na solução de cloreto de cálcio $(0,1 \mathrm{M})$ foi investigado visando verificar sua influência no percentual de remoção. As condições dos experimentos de descoloração foram: solução de azul de metileno de $15 \mathrm{mg} / \mathrm{L}$, $6 \mathrm{mg} / \mathrm{L}$ de peróxido de hidrogênio, a $30^{\circ} \mathrm{C}$ com agitação constante a 100 rpm, por 240 minutos.

Foi ainda testada uma etapa de lavagem das esferas de alginato de cálcio, com a enzima imobilizada, com água destilada logo após o procedimento de imobilização. Estas esferas foram separadas por centrifugação a 5.000 rpm por 10 minutos. Foram testadas cargas de enzima de 25 e $50 \mathrm{U} / \mathrm{mL}$. Foram conduzidos experimentos de controle com as esferas contendo enzimas imobilizadas, nas mesmas condições, porém sem a adição de peróxido de hidrogênio.

\subsection{Efeito da reutilização das enzimas imobilizadas na descoloração do corante.}

Estes experimentos foram realizados visando avaliar o desempenho das enzimas imobilizadas na descoloração de azul de metileno (15 mg/L). O mesmo lote de enzimas imobilizadas (tempo de cura de 5 dias) foi reutilizado a intervalos de 24 horas, e mantidas em água destilada a $4^{\circ} \mathrm{C}$. Um lote recém preparado (120 minutos de tempo de cura) foi utilizado de forma seqüencial após o preparo deste. As condições utilizadas durante o processo de descoloração foram: carga de enzimas imobilizadas de $50 \mathrm{U} / \mathrm{mL}$, azul de metileno a $15 \mathrm{mg} / \mathrm{L}$, peróxido de hidrogênio a $6 \mathrm{mg} / \mathrm{L}, 30^{\circ} \mathrm{C}$, 100 rpm,. Para avaliação do valor da absorvância após a reação enzimática foram adotados tempos de 240 minutos e de 180 minutos para os experimentos com intervalos de 24 horas e os realizados no mesmo dia, respectivamente. 


\section{RESULTADOS E DISCUSSÃO}

Para as esferas de alginato de cálcio (1\%), sem enzimas retidas em seu interior, testes de remoção percentual de cor por adsorção indicam um valor médio de $5 \%$. Para as concentrações de azul de metileno testadas de 5, 10, 15 e $20 \mathrm{mg} / \mathrm{L}$ os percentuais de descoloração foram 13,0\%, 11,5\%, $11,9 \%$ e 8,8\%, para tempos de reação de 60, 120 e 180 minutos de reação. Nos experimentos subsequentes foi utilizada solução com 15 mg/L de AM nos testes de descoloração. A influência do tempo de contato pode ser observada na Figura 3, onde para concentração de $6 \mathrm{mg} / \mathrm{L}$ de peróxido de hidrogênio apresentou os maiores percentuais de descoloração enzimática do azul de metileno, com valor máximo de 10,7 \% para 120 minutos de reação.

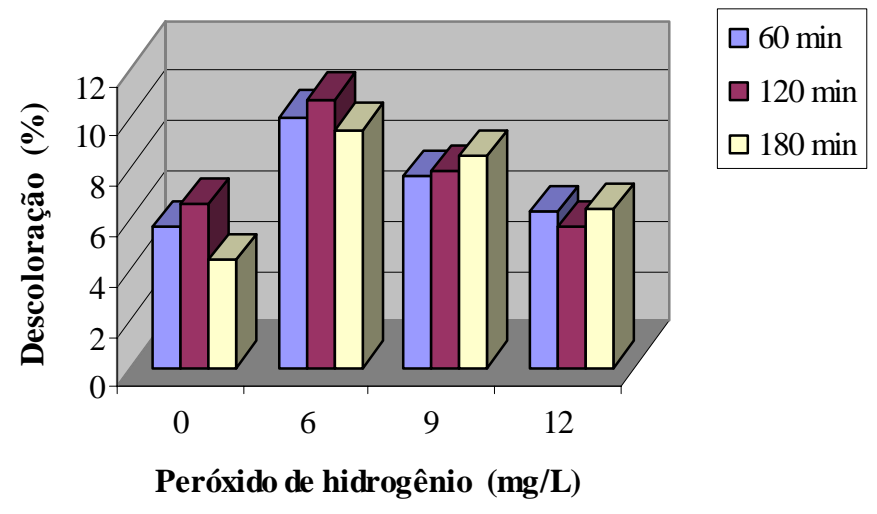

Figura 3. Efeito da concentração de peróxido de hidrogênio e do tempo de reação.

O tempo de cura utilizado na metodologia de imobilização foi avaliado (Figura 4), visando verificar sua influência na descoloração, não sendo observadas diferenças significativas.

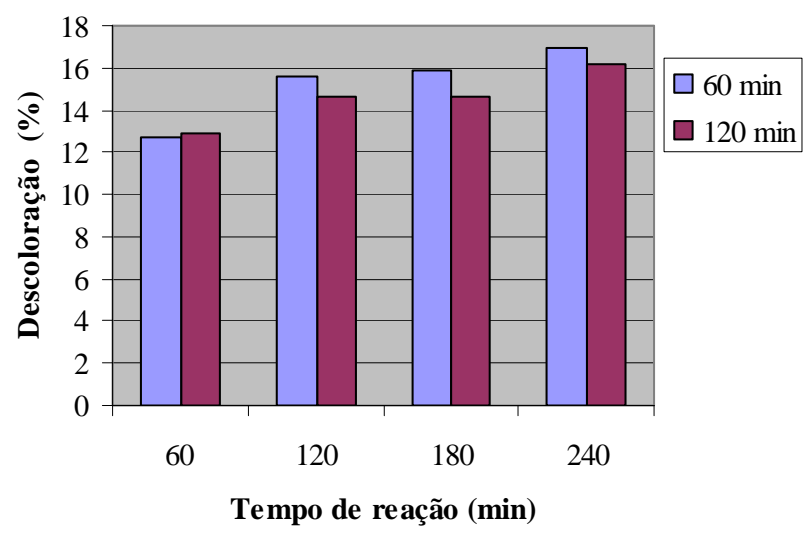

Figura 4. Efeito do tempo de cura da esfera de alginato de cálcio na descoloração de AM. 
Entretanto, nos experimentos realizados com esferas de alginato de cálcio (2\%) e tempo de cura de 120 minutos, maior robustez e resistência mecânica foram observadas, ao reutilizá-las em ciclos sucessivos, quando comparadas com aquelas que permaneceram por 60 minutos em solução de cloreto de cálcio após a imobilização.

A influência da carga de enzima foi motivo de investigação visando identificar sua influência. A Figura 5 apresenta os valores de remoção de cor obtidos para cargas de $25 \mathrm{U} / \mathrm{mL}$ e $50 \mathrm{U} / \mathrm{mL}$. Descoloração na ordem de $14 \%$ foi verificada para o sistema com esferas preparadas com carga de $50 \mathrm{U} / \mathrm{mL}$, e de até $9,9 \%$ para as geradas com carga de $25 \mathrm{U} / \mathrm{mL}$ e após 240 minutos de reação.

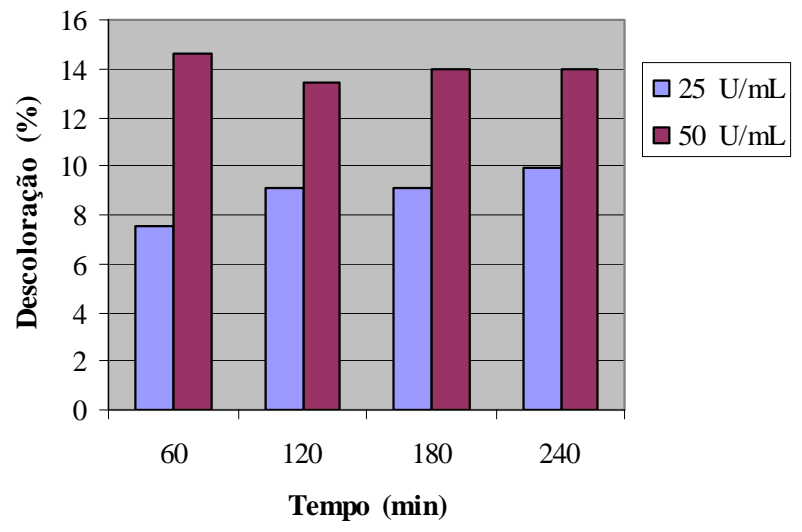

Figura 5. Efeito da carga de enzima imobilizada na descoloração da solução 15 mg/L de AM.

$\mathrm{Na}$ reutilização das esferas em procedimentos sequenciais com intervalos de 24 horas foi possível observar uma redução da remoção de cor de cerca de 20 \% no primeiro ciclo, para 6,9 \% no segundo, nas condições testadas, conforme apresentado na Figura 6.

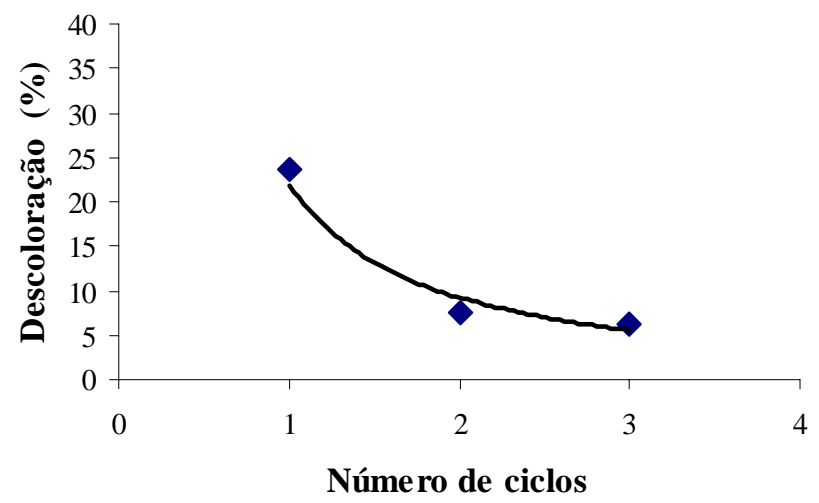

Figura 6. Efeito da reutilização da enzima imobilizada na descoloração de solução de AM. 


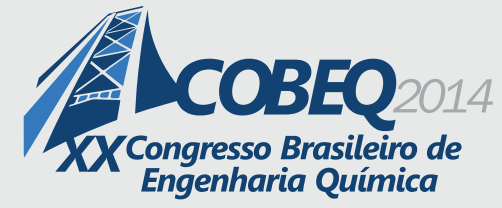

As esferas contendo a enzima HRP recém preparadas propiciaram uma descoloração média de $14 \%$ no primeiro ciclo. Entretanto, ao serem reutilizadas em segundo ciclo reacional sequencial no mesmo dia não apresentaram atividade. Gholami-Borujemi et al. (2011) reportaram um número de 10 ciclos para a reutilização de Horseradish peroxidase imobilizadas em esferas de alginato de cálcio ( $2 \%$ p/v) para corante azo com eficiências de descoloração na faixa de 80 a $10 \%$, em pH 7,4 a $25^{\circ} \mathrm{C}$ após 90 minutos de reação. Maddhinni et al. (2006) apresentaram percentuais de cerca de $50 \%$ de remoção para descoloração de corante azo (amarelo-12) utilizando Horseradish peroxidase imobilizada em esferas de alginato de cálcio, $\mathrm{pH} 4,0,24^{\circ} \mathrm{C}$, tempo reacional de 1 hora e 45 minutos, obtendo cerca de 50\% de remoção de cor, com até 3 ciclos de reutilização.

\section{CONCLUSÕES}

A viabilidade técnica da aplicação da metodologia de descoloração do corante azul de metileno promovida pela enzima Horseradish peroxidase imobilizada em esferas de alginato de cálcio foi verificada, indicando cerca de 5 \% de remoção ocorrida devido a adsorção. Para os ensaios realizados com solução $15 \mathrm{mg}$ de azul de metileno/L e solução de peróxido de hidrogênio $6 \mathrm{mg} / \mathrm{L}$, com as esferas de alginato de cálcio $2 \%$ e $50 \mathrm{U} / \mathrm{mL}$ de enzimas retidas, foi possível observar percentuais de cerca de 20 \% de descoloração. Novos ensaios estão em andamento visando elevar este percentual a valores aceitáveis de forma que este procedimento passe de condição de polimento final para uma etapa efetiva de tratamento de efluentes líquidos industriais.

\section{REFERÊNCIAS}

GHOLAMI-BORUJEMI, F.; MAHVI, A. H.; NASERI, S.; FARAMARZI, M. A.; NABIZADEH, R.; ALIMOHAMMADI, M. Application of immobilized horseradish peroxidase for removal and detoxification of azo dye drom aquous solution. Res. J. Chem. Environ., v. 15, n. 2. p. 217-222, 2011.

HAMEED, B.; AHMAD, A.; LATIFF, K. Adsorption of basic dye (methilene blue) onto activated carbon prepared from rattan sawdust. Dyes and Pigments, v. 75, n 1, p. 143-149, 2007.

KUNZ, A.; PERALTA-ZAMORA, P.; de MORAES, S.G.; DURÁN, N. Novas tendências no tratamento de efluentes têxteis, Q. Nova, v. 25, n. 1, p. 78-82, 2002.

MADDHINNI, V. L.; VURIMINDI, H. B.; YERRAMILLI, A. Degradation of azo dye with horseradish peroxidase (HRP). J. Indian Inst.Sci., v. 86, p. 507-514, 2006.

MUGDHA, A.; USHA, M. Enzymatic treatment of wastewater containing dyestuffs using different delivery systems. Sci. Revs. Chem. Commun., v. 2, n 1, p. 31-40, 2012.

NICELL, J. A.; WRIGHT, H. A model of peroxidase activity with inhibition by hydrogen peroxide. Enz. Microb. Technol., v. 21, n. 4, p. 302-210, 1997.

ONDER, S.; CELEBI, M.; ALTIKATOGLU, M.; HATIPOGLU, A.; KUZU, H. Decolorization of 


\section{ACoseQ 势 Engenharia Química}

19 a 22 de outubro de 2014

Florianópolis/SC

Naftol Blue Black using the Horseradish peroxidase. Appl. Biochem.Biotechnol., v. 163, n. 3, p. 433443, 2011.

SILVA, M.C.; CORREA, A. D.; TORRES, J. A.; AMORIM, M. T. S. P. Descoloração de corantes industriais e efluentes têxteis simulados por peroxidase de nabo (Brassica campestre). Q. Nova, v. 35, n. 5, p. 889-894, 2012. 